\title{
El subsistema de universidades interculturales en México. Entre la política social y la política educativa*
}

The intercultural universities subsystem in Mexico. Between social and education policies

Luis Arturo Tapia Guerrero**

\section{RESUMEN}

El trabajo propone una línea de discusión según la cual las universidades interculturales se habrían generado en un espacio de convergencia entre tres componentes: por un lado, las metas de la política social (abocada al combate a la pobreza); por otro, una política de educación superior orientada a la expansión de la matrícula y a la formación de capital humano; $y$ finalmente, la agenda de interculturalidad promovida en los últimos años por el movimiento indígena nacional e internacional. Este campo de convergencia sugiere que en sus inicios este subsistema de universidades estuvo lejos de constituir un mero componente de las políticas de educación superior. Tampoco fue el resultado de una apertura gubernamental para avanzar hacia una compleja reconfiguración del viejo Estado-nación en aras de un Estado pluricultural. Antes bien, se planteó como un instrumento de la política social de los gobiernos federales en tanto mecanismo con el que se pretendía generar oportunidades de educación para los jóvenes de pueblos originarios y una reducción de los índices de marginación entre dichos pueblos, lo que supone una instrumentalización 0 reducción en detrimento de las demandas contenidas en la agenda de interculturalidad.

Palabras clave: Educación intercultural, universidades interculturales, políticas educativas

\section{ABSTRACT}

The paper argues that intercultural universities derived from the convergence of three components: first, the goals of social policy (relative to poverty reduction); secondly, a policy of higher education aimed at increasing enrollment and training of human capital; and finally, the agenda of interculturalism promoted in recent years by the national and international indigenous movement. This suggests that, initially, this university subsystem was far from being a mere component of higher education policy, nor was it the result of the government's willingness to advance a complex reconfiguration of the old nation-state in favor of a pluricultural state. Rather, it was conceived as an instrument of social policy by the federal government as a mechanism intended to create educational opportunities for the youth of indigenous peoples, and to reduce marginalization levels among these peoples, which is a manipulation or reduction of the demands of the interculturalism agenda.

Key words: Intercultural education, intercultural universities, education policy

*Este texto se preparó en el marco del proyecto de investigación: "Políticas de interculturalidad en la educación superior en Oaxaca. Proyectos educativos etnopolíticos en la construcción de un campo social" del CIESAS unidad Pacífico Sur.

* Catedrático CONACYT. Centro Interdisciplinario de Investigación para el Desarrollo Integral Regional. Unidad Oaxaca; luis.arturo.tapia@gmail.com 


\section{INTRODUCCIÓN}

La creación del subsistema de Universidades Interculturales (UI) en México se inscribe dentro del conjunto de acciones de política pública implementadas durante las últimas dos décadas por parte de los gobiernos federales en atención a diversas demandas de los pueblos originarios del país, entre otras, la de acceder a una educación superior cultural y lingüísticamente pertinente (Casillas M. y Santini V., 2006).

El subsistema de UI gestionado por la Coordinación General de Educación Intercultural Bilingüe (CGEIB), adscrita a la Secretaría de Educación Pública (SEP), suma a la fecha doce universidades en igual número de entidades federativas, lo que plantea a los observadores externos múltiples interrogantes en torno a la organización, currículum, oferta educativa y modelo de interculturalidad que promueven, además de la relación que sostienen con los contextos comunitarios, con las poblaciones indígenas y los mercados de trabajo, entre otros temas que a la fecha han propiciado un voluminoso cuerpo de estudios. ${ }^{1}$

Dos cuestiones en las que es necesario profundizar a fin de ampliar la compresión en torno al desarrollo de este subsistema de universidades -que en promedio no rebasan nueve años de antigüedad desde su establecimiento, en 2003- son, por un lado, el hecho de que haya sido bajo gobiernos del Partido Acción Nacional (PAN) -a los que tradicionalmente no se les reconoce una cercanía con la agenda de derechos indígenas e identitarioscuando se creó el subsistema, siendo que por sus rasgos la educación intercultural suele asociarse a una agenda de derechos más bien cercana a movimientos sociales y políticos contestatarios (algunas de estas posturas se documentan en López, 2009). Por otro

\footnotetext{
${ }^{1}$ Es imposible y rebasa los objetivos de este trabajo presentar el estado del arte en los estudios generados en torno a las UI tanto en México como en otros países de América Latina. Una idea acerca de las distintas disciplinas y de las distintas miradas que se han abocado al tema se puede ver en los siguientes trabajos y otros que se refieren en el cuerpo de este documento (Alonso G., Hernández A., y Solís C., 2014; Bastiani G. y Moguel V., 2010; Bertely B., María, 2011; Castro R., 2005; Deance y Vázquez V., 2010; Dietz, 2014a; González O., 2004, 2007a; Huerta M. y García P., 2013; Lehmann, 2012; Mendoza Z., 2009, 2013; Molina F., 2012; Sandoval, González y Téllez, 2006; Valdez R. y Romero L., 2011). María Bertely y otros ofrecen un estado del arte sobre la educación intercultural de los distintos niveles educativos en un volumen preparado dentro de la colección de estados del conocimiento del COMIE (Bertely B., María, Dietz, G. y Díaz T., 2013).
} 
lado, se debe indagar más en los alcances y límites que presentan las UI como respuesta gubernamental a las demandas contenidas en esa o esas agendas. ${ }^{2}$ Sobre estas cuestiones, y partiendo de una revisión de la literatura sobre el tema, en las siguientes páginas se propone una línea de discusión según la cual las UI se habrían generado en un espacio de convergencia entre tres componentes contextuales: por un lado, las metas de la política social (abocada en los últimos ańos al combate a la pobreza); por otro, una política de educación superior (ES) orientada a la expansión de la matrícula y a la formación de capital humano; y finalmente, la agenda de interculturalidad promovida en los últimos años por una coalición de actores abocados a avanzar en el reconocimiento de un conjunto de derechos identitarios, y al frente de la cual se puede ubicar al movimiento indígena nacional e internacional. Este campo de convergencia sugiere que en sus inicios el subsistema de UI estuvo lejos de constituir un mero componente de las políticas de educación superior. Tampoco fue el resultado de una apertura gubernamental para avanzar hacia una compleja reconfiguración del viejo Estado-nación en aras de construir un Estado pluricultural. Antes bien, de forma reducida, las UI se plantearon como un instrumento de la política social de los gobiernos federales en cuanto instrumentos con los que se pretendía generar oportunidades de educación para los jóvenes de pueblos originarios y la formación de capital humano, esperando mejorar con ello los indicadores de acceso a los servicios educativos y reducir los índices de marginación entre dichos pueblos. Pero la agenda de interculturalidad de los actores etnopolíticos parece ir muchas veces más allá de esta estrategia.

\footnotetext{
${ }^{2}$ El campo de la interculturalidad en realidad se refiere a un fenómeno marcado por la heterogeneidad de actores y de proyectos, y junto con ello a tensiones y conflictos entre distintas interculturalidades. Para fines expositivos y analíticos se refiere aquí una agenda de interculturalidad en singular; sin embargo, como queda dicho y como se argumenta en el apartado final, en realidad se trata de una agenda plural. Además, se debe advertir que el término mismo de interculturalidad no resulta ni de uso ni de significados unívocos entre los actores locales (González A., 2009; Hernández, 2007; Pérez R., 2009), por lo que la idea misma de una agenda de interculturalidad resulta aún más compleja. No obstante, se sugiere que existe un hilo conductor dentro de esta diversidad de proyectos de interculturalidad vinculados con un conjunto de derechos identitarios, y al frente de la cual se puede ubicar al movimiento indígena nacional e internacional. Estos derechos suponen, en última instancia, la reconfiguración de las relaciones entre los pueblos originarios, la sociedad y los poderes públicos.
} 
De lo anterior se sigue que, aunque en términos formales las UI se ofrecieron como un modelo universitario adaptado a los contextos rurales e indígenas con pertinencia cultural y lingüística (Dietz, 2014b), la subordinación real del subsistema a la política social hizo del modelo oficial una reducción o instrumentalización de la interculturalidad, en menoscabo de la naturaleza y contenidos de la agenda de derechos y demandas impulsada por actores etnopolíticos que, como se discute en el cuarto apartado, supone en última instancia y de manera amplia la reconfiguración de las relaciones entre los pueblos originarios, la sociedad y los poderes públicos.

Si como han argumentado otros autores (Casillas M. y Santini V., 2006), el subsistema de UI es la respuesta a una demanda creciente de educación superior por parte de los pueblos originarios, la vinculación de este proyecto con las metas de política social se tradujo en una situación que priorizaba simplemente la ampliación de la matrícula de jóvenes indígenas cursando estudios de nivel superior, en detrimento de la construcción de la pertinencia en la organización y en los programas al interior de las UI, y en el de la atención a una demanda de interculturalidad que no se circunscribe al campo educativo, lo que afecta de raíz las posibilidades de articulación entre las acciones de política orientadas a la interculturalidad y las demandas y proyectos que impulsan la multiplicidad de agentes etnopolíticos desde lo local.

Para decirlo en breve, el trabajo discute que parece existir una tensión de fondo entre la agenda de actores que desde lo local impulsan la interculturalización de las relaciones sociales, y la respuesta emprendida desde lo gubernamental -concretamente el subsistema de UI- como correlato de una política social, al menos, durante los sexenios panistas. ${ }^{3}$ Se plantea también que estas reducciones revelan un estancamiento en el proceso de configuración de la política de interculturalidad en el país, tal como la demandaría el cumplimiento del artículo $2^{\circ}$ constitucional y el

\footnotetext{
${ }^{3}$ Esta delimitación temporal que distingue la fase de los gobiernos panistas de la fase actual bajo el PRI es importante, porque la publicación del Programa Especial de Educación Intercultural (PEEI) 2014-2018 -al que se hace referencia en el último apartado- ofrece signos de lo que pareciera un nuevo énfasis en la tarea de construcción del modelo de interculturalidad a nivel de las IES.
} 
Convenio 169 de la Organización Internacional del Trabajo que el país ratificó en 1991 .

El documento se organiza en cuatro apartados. En el primero se hace un recuento breve de las acciones de política pública que en los últimos ańos se orientaron a atender demandas relativas a la interculturalidad. En el segundo se avanza en la idea de que las acciones señaladas estuvieron fuertemente condicionadas por la política social del gobierno federal, que en los últimos años ha estado caracterizada por la adscripción a un paradigma desarrollista orientado al mercado exterior, y la centralidad de la estrategia de combate a la pobreza.

En el tercer apartado se plantea que la política de educación superior de los últimos gobiernos acercó sus metas a la expansión de la matrícula y de la oferta educativa como estrategia para incrementar el capital humano y la competitividad del país, inmerso ya en la dinámica del mercado externo. En este contexto, la creación de un subsistema de UI no enfrentaba tensiones ni con la política educativa ni con la social, lo que facilitó su adopción por parte de los gobiernos del PAN.

En el cuarto apartado se describe la agenda de interculturalidad como un conjunto de demandas, actores y proyectos heterogéneos asociados al desarrollo del movimiento indígena tanto nacional como internacional. Se argumenta que, si bien el área de convergencia entre la política social y la política educativa explican la expansión de la oferta y de la matrícula de las instituciones de educación superior (IES), el modelo específico de las UI trasluce una influencia o efecto del avance de la agenda de interculturalidad de los últimos años; es decir, su visibilidad en la esfera pública y su traslado a la agenda gubernamental.

En el quinto apartado se plantean algunas reflexiones en las que se discuten las tensiones y los límites de la estrategia gubernamental para atender la agenda de interculturalidad y se problematiza en las condicionantes de ello. 


\section{ACCIONES DE POLÍTICA PÚBLICA ORIENTADAS A LA INTERCULTURALIDAD}

En México, las acciones de política orientadas a la atención de los pueblos originarios no son recientes. En particular no lo son las relativas al campo educativo. Baste recordar, por ejemplo, que ya en una época temprana, como 1926, se fundó en la capital del país la Casa del Estudiante, que reunió a 200 jóvenes de 26 etnias a quienes se impartía la enseńanza tradicional en castellano, al tiempo que se fomentaba el uso de las lenguas vernáculas en horas extracurriculares (Maurer Á., 2010). Poco después, en 1937, se creó el Departamento de Educación Indígena, como un área especial dentro de la SEP (Castro G., 2009). En 1940, con el auspicio de Lázaro Cárdenas, se celebró en Pátzcuaro el 1er. Congreso Indigenista Interamericano del que derivó la administración del programa para el bienestar del indio (Maurer Á., 2010).

No es el objetivo enlistar ni resumir aquí la historia de las políticas indigenistas en el país. Un recuento general de los que la propia Comisión Nacional para el Desarrollo de los Pueblos Indígenas (CDI) identifica como periodos remarcables a raíz de las metas y estrategias seguidas por los gobiernos en relación con los pueblos originarios indica que, entre 1948 y 1970, tuvo lugar un periodo en el que la meta central fue "integrar a los indígenas a la cultura nacional", "aculturándolos" en las "regiones de refugio" (CDI, 2012: 7). En estos años se estableció el primer Centro Coordinador Indigenista (CCI); además, se inauguró el Museo Nacional de Artes e Industrias Populares, se crearon las primeras modalidades de albergues escolares para niños indígenas, se implantó de manera oficial el Sistema de Educación Bilingüe-Bicultural, iniciado por el INI, entre otras acciones (ibid.).

Entre 1970 y 1976 se registró otro periodo en el que el objetivo de la política indigenista se inscribió dentro de una estrategia de regionalización del desarrollo, lo que suponía la integración de los pueblos indígenas a dichas estrategias (ibid.). De estos años es el establecimiento de talleres y pequeñas industrias en zonas indígenas y la creación de buen número de los referidos centros coordinadores, además de un sistema de albergues escolares en el medio rural e indígena (ibid.). 
En abierto contraste, hacia mediados y finales de los ochenta se observó un periodo en el que el discurso oficial comenzó a referirse a México como un país plural en lo étnico, en lo cultural y en lo ideológico y que debía “...encontrar el equilibrio integrador entre el acceso a la modernidad económica, el respeto a la diversidad social y el fortalecimiento de la unidad nacional" (ibid.: 21). Este discurso se planteó ya en la víspera de la ratificación del Convenio 169 de la OIT por parte de México, en 1991, y de las reformas al artículo $4^{\circ}$ constitucional que derivaron de ello en 1992.

La tarea de encontrar el equilibrio integrador entre el acceso a la modernidad económica, el respeto a la diversidad cultural y el fortalecimiento de la unidad nacional a finales de la década de los ochenta, derivó en una tarea compleja que, hacia el fin de los noventa, se planteaba como la necesidad de construir una nueva relación entre los pueblos indígenas, la sociedad y el gobierno (ibid.), encomienda esta que, aunque dista claramente de la que se había planteado en 1948 en torno a la aculturación de los pueblos indígenas, está hoy lejos de concretarse, como se discute en el último apartado de este trabajo.

El periodo actual se enmarca dentro de la estrategia planteada durante la primera década del siglo -bajo los gobiernos del PAN-, según la cual el desarrollo integral y sustentable de los pueblos y comunidades indígenas requería de la acción transversal de todas las instituciones (CDI, 2012). De esta manera, los años recientes han visto multiplicarse las acciones de política pública orientadas a la atención de los grupos étnicos y que aquí se enuncian como acciones orientadas a la interculturalidad. ${ }^{4} \mathrm{~A}$ este respecto se pueden mencionar las reformas al marco normativo en favor de los derechos indígenas durante las últimas dos décadas (artículos $2^{\circ}$

\footnotetext{
${ }^{4}$ Como ya se mencionó en la nota al pie número 2 (vid. Supra), el uso y los significados del término interculturalidad se han vuelto un campo de pocos acuerdos (Hernández, 2007; Pérez R., 2009). El término suele contrastarse con otros como multiculturalismo o comunalismo en el contexto oaxaqueño (Maldonado A., 2006). La diversidad de usos y de enfoques plantea abiertamente el estatus polisémico del término (González A., 2009). Para los fines de este trabajo se entiende la interculturalidad como un proyecto social y político orientado a horizontalizar las relaciones entre las minorías étnicas y las sociedades mayoritarias, lo que supone no solo el reconocimiento de un conjunto de derechos identitarios, sino la reconfiguración del viejo modelo de Estado-nación fundado en el supuesto de la monoculturalidad y de la identidad nacional.
} 
y $4^{\circ}$ constitucionales), la creación de leyes reglamentarias y de órganos orientados pretendidamente a prevenir la discriminación (v. gr. el Consejo Nacional para Prevenir la Discriminación), o a impulsar el desarrollo de los pueblos indígenas $(v . g r$. la referida CDI) o a promover una oferta educativa culturalmente pertinente en el nivel superior $(v \cdot g r$. la Coordinación General de Educación Intercultural Bilingüe), o a preservar la identidad y cultura de los pueblos originarios $(v . g r$. el Instituto Nacional de las Lenguas Indígenas). A ello habría que agregar la creación de programas compensatorios en salud y en educación orientados a atender poblaciones indígenas (Sandoval F. y Guerra G., 2007). ${ }^{5}$ Finalmente, cabría agregar a esta lista la creación del subsistema de UI, quizá la acción más visible y relevante en materia de interculturalidad de los últimos años y en la que este trabajo se concentra.

En los siguientes subapartados se detallan algunas de estas acciones de política.

\section{Reformas al marco constitucional}

Con la reforma al artículo $4^{\circ}$ constitucional en 1992, se reconoció la composición pluricultural del país, que se ratificó y se reubicó en la reforma al artículo $2^{\circ}$, en 2001 . Este artículo señala a la letra que "La Nación tiene una composición pluricultural sustentada originalmente en sus pueblos indígenas que son aquellos que descienden de poblaciones que habitaban en el territorio actual del país al iniciarse la colonización y que conservan sus propias instituciones sociales, económicas, culturales y políticas, o parte de ellas" (Art. $2^{\circ}$, Constitución Política de los Estados Unidos Mexicanos, CPEUM). En los párrafos siguientes, el artículo plantea el reconocimiento a la libre determinación de estos pueblos. ${ }^{6}$

\footnotetext{
${ }^{5}$ En lo relativo a la salud, la Secretaría del ramo creó, en 2001, la Coordinación de Salud para los Pueblos Indígenas con el propósito de lograr que los programas de salud alcanzaran con eficiencia y efectividad a estos sectores de la población. En 2004 las funciones de la Coordinación se integraron al Sistema Nacional de Protección Social en Salud, en la Dirección de Programas Estratégicos en Áreas Rurales e Indígenas de la Dirección General de Gestión de Servicios de Salud, con base en el artículo 10, fracción XI, Capítulo Segundo del Reglamento Interior del Sistema Nacional de Protección Social en Salud (véase Secretaría de Salud, 2001).

${ }^{6}$ Jorge Alberto González Galván ofrece, en el conjunto de su obra (1994, 1995, 1997, 1999, $2000,2002)$, un análisis pormenorizado de estas reformas, así como de otros pasajes constitucionales relativos a los derechos indígenas de las últimas décadas.
} 
De particular importancia resulta el apartado B del mismo artículo, en el que se establece la obligación de la Federación, de los Estados y de los Municipios, de:

...promover la igualdad de oportunidades de los indígenas y eliminar cualquier práctica discriminatoria, establecerán las instituciones y determinarán las políticas necesarias para garantizar la vigencia de los derechos de los indígenas y el desarrollo integral de sus pueblos y comunidades, las cuales deberán ser diseñadas y operadas conjuntamente con ellos. Para abatir las carencias y rezagos que afectan a los pueblos y comunidades indígenas... (Art. $2^{\circ}$, Apdo. B, CPEUM).

Sigue el apartado con un listado pormenorizado de las materias en las que los distintos niveles de gobierno han de promover el bienestar de las poblaciones indígenas. Por ejemplo:

- Impulsar el desarrollo regional, las economías locales y mejorar las condiciones de vida (Fracc. I).

- Incrementar los niveles de escolaridad, favorecer la educación bilingüe e intercultural, y otras acciones educativas (Fracc. II).

- Asegurar el acceso a los servicios de salud y apoyar la nutrición (Fracc. III).

- Consultar a los pueblos indígenas en la elaboración del Plan Nacional de Desarrollo y de los estatales y municipales y, en su caso, incorporar las recomendaciones y propuestas que realicen (Fracc. IX).

Se debe subrayar el hecho de que, según la referida fracción II, la provisión de educación intercultural es un mandato constitucional para los gobiernos.

Del artículo $2^{\circ}$ se pueden destacar dos rasgos: primero, el dispositivo formal mediante el que se estableció la política de reconocimiento de los derechos identitarios; y segundo, su contenido podría ser el fundamento de una política específica de interculturalidad, que actualmente no existe como tal. Por supuesto, esta lectura propicia una discusión acerca de si sería posible una política tal o si la naturaleza del tema intercultural o indígena solo es abordable a través de una política transversal con el riesgo 
constante de la desarticulación y de los reduccionismos que se observan en su contenido actualmente.

Por otro lado, la reforma constitucional al artículo $1^{\circ}$ en 2001 prohibió cualquier tipo de discriminación hacia las personas, con una mención específica de aquella ejercida contra los pueblos indígenas. De esta reforma derivaron la actual Ley Federal para Prevenir la Discriminación (de 2003) y su órgano operador denominado Consejo Nacional para la Prevención de la Discriminación (CONAPRED) del mismo año. $\mathrm{Al}$ respecto se puede agregar que el artículo $3^{\circ}$ (frac. II) reconoce en la educación un recurso de coadyuvancia para superar prácticas discriminatorias. ${ }^{7}$

Un recuento más o menos detallado de otros cambios al marco normativo en materia de interculturalidad se puede revisar en el trabajo de Ahuja y sus colaboradores (2004). A continuación se mencionan algunos de dichos cambios. Por ejemplo, en 2012 se promulgó la Ley General de Derechos Lingüísticos de los Pueblos Indígenas, que regula el "...reconocimiento y la protección de los derechos lingüísticos, individuales y colectivos de los pueblos y comunidades indígenas [y promueve] el uso y desarrollo de las lenguas indígenas" (Art. $1^{\circ}$ ). Esta Ley reconoce las lenguas indígenas como lenguas nacionales y les otorga la misma validez que al español en el territorio, localización y contexto en que se hablan (Art. $4^{\circ}$ ). Esto supone que todas son válidas para efectos de cualquier asunto o trámite de carácter público, así como para acceder plenamente a la gestión, los servicios y la información pública (Ahuja S., Berumen C., Casillas M., y Crispín B., 2004).

El artículo 11 de esta misma Ley establece el deber del Estado de garantizar el acceso a la educación obligatoria en la modalidad intercultural y bilingüe para la población indígena. La promulgación de esta Ley reformó la fracción IV del artículo $7^{\circ}$ de la Ley General de Educación, reglamentaria del $3^{\circ}$ constitucional. Esta fracción establece el acceso a la educación obligatoria tanto en lengua materna como en español para los grupos indígenas. A su vez, el artículo 38 señala que, "La educación básica, en sus tres niveles, tendrá las adaptaciones requeridas para responder a las características lingüísticas y culturales de cada uno de los diversos

\footnotetext{
${ }^{7}$ Algunos trabajos que detallan estas disposiciones jurídicas son: Ahuja S. et al., 2004; Hevia R., Hirmas R., Treviño y Marambio V., 2005).
} 
grupos indígenas del país, así como la población rural dispersa y grupos migratorios".

De más reciente creación, la Ley General de Desarrollo Social (2013) tiene por objeto garantizar el ejercicio pleno de los derechos sociales, individuales y colectivos, así como regular los mecanismos de su observancia (Ahuja S. et al., 2004). En su artículo $3^{\circ}$ establece los principios en que debe sustentarse dicha política -entre los cuales menciona el respeto a la diversidad, a la libre determinación y a la autonomía de los pueblos indígenas y de sus comunidades.

Basten estas referencias para evidenciar el hecho de que la creación o reforma del marco jurídico en los últimos años ha formado parte del conjunto de acciones de política pública orientadas a la interculturalidad lo que, sin duda, revela la inserción de un componente nuevo en la agenda de los últimos gobiernos, así como un avance en el peso social y político de los actores y de los movimientos étnicos en el país.

\section{El giro discursivo en las políticas de educación superior}

Durante las últimas décadas el discurso oficial reconoció la necesidad de dar participación en las oportunidades de formación y de desarrollo a grupos sociales focalizados según su necesidad económica, religión, etnia, raza, idioma, cultura, género y discapacidad (Aponte H., 2008). Esta tendencia hacia la inclusión ha caracterizado las políticas de educación superior en la mayoría de los países de la región a partir de los noventa (Chiroleu, 2009). ${ }^{8}$ Esta tendencia contrasta con la de los ańos ochenta, cuando los enormes niveles de endeudamiento externo y los procesos de inserción de las economías de cada país a la economía mundial excluyeron el tema de la equidad de los objetivos de la política educativa (Reimers, 2000). ${ }^{\text {? }}$

${ }^{8}$ El tema de la equidad educativa se puede identificar desde el Programa de Desarrollo Educativo 1995-2000 del gobierno de Ernesto Zedillo, en el que se planteaba como meta alcanzar una mayor justicia y equidad educativa con la atención compensatoria a las poblaciones en condiciones de mayor rezago (i. e. pequeñas, indígenas, migrantes y niños de la calle) (Hevia R. et al., 2005).

${ }^{9}$ Los términos equidad, igualdad, inclusión no son equivalentes, pero por sí mismos dan lugar a un cuerpo de literatura abundante. Para los fines de este apartado no es necesario reseñar la discusión existente. Si el lector busca un acercamiento sobre los significados en 
La inclusión en la educación superior vino a ser, en los últimos ańos, una estrategia vinculada a condiciones de equidad para el acceso, la permanencia y la culminación de los estudios (Aponte H., 2008). ${ }^{10}$ En este sentido, las políticas se han ido distanciando de los criterios de acceso basados en la excelencia, el mérito y el esfuerzo individual (Chiroleu, 2009).

El discurso de la equidad educativa parte del reconocimiento de una distribución desigual de las habilidades para el ascenso social. Por eso, la equidad supone el establecimiento de discriminaciones positivas que traten de forma desigual a los desiguales, a fin de permitir alcanzar similares resultados y con ello similares oportunidades (ibid.). Al respecto, se debe observar que solo entre 2007 y 2008 el gobierno federal creó cinco programas educativos orientados a la equidad:

- Fortalecimiento de la Educación Especial y de la Integración Educativa (2007).

- Programa Asesor Técnico Pedagógico y para la Atención Educativa a la Diversidad Social, Lingüística y Cultural (2008).

- Atención Educativa a Grupos en Situación Vulnerable (2008).

- Educación para Personas con Discapacidad (2008).

- Fortalecimiento a las Acciones Asociadas a la Educación Indígena (2008).

Todos estos programas fueron integrados en uno nuevo, denominado Programa para la Inclusión y la Equidad Educativa, en 2014.

El giro discursivo hacia la equidad educativa abonó en la expansión de la oferta de educación superior y en los dispositivos para dar acceso a la misma, además de que estuvo en la génesis de

\footnotetext{
el marco de la educación superior, puede revisar algunos trabajos que a continuación se refieren (Alcántara, 2013; Alcántara S. y Navarrete C., 2014; Aponte H., 2008; Bastiani G. y Moguel V., 2010; Chiroleu, 2009).

${ }^{10} \mathrm{Sin}$ embargo, los progresos en la meta de acceso a la educación superior sacaron a la luz nuevas formas de inequidad, luego de que los grupos antes excluidos mostraron rezagos en sus capacidades de aprendizaje, como un efecto inesperado del rezago generado por las desigualdades previas vinculadas a las distintas formas de exclusión (v. gr. pobreza, género, raza, etnia, idioma y capital cultural). Esto planteó nuevas inequidades en las experiencias educativas (Aponte H., 2008).
} 
un conjunto de iniciativas que, desde el gobierno y fuera de este, buscaron acompañar el paso de estudiantes indígenas en las IES.

Esta perspectiva de la equidad vio en las becas una herramienta esencial para impedir que el origen social condicionara el destino educativo de las personas (Tuirán, 2012).

Una estrategia específica encaminada a promover la señalada equidad fue el Programa Nacional de Becas para la Educación Superior (Pronabes), creado en 2001 (Casillas M. y Santini V., 2006). Su propósito manifiesto fue y ha sido mejorar el acceso y la permanencia de estudiantes de bajos recursos en las IES (Mateos C., Mendoza Z., y Dietz, 2013). ${ }^{11}$

Según cálculos de Alcántara y Navarrete (2014), en los últimos ciclos escolares se registró una participación creciente de estudiantes indígenas en el Programa. Por ejemplo, para el ciclo 2003-2004, 4\% de los becarios lo eran; cifra que subió a 5.4\% en el ciclo 2006-2007, y luego a 6.1\% en 2007-2008; para 2011-2012, ya había alcanzado $12.6 \%$.

CUADRO 1. Número de becas Pronabes según ciclo escolar

\begin{tabular}{|l|c|c|c|c|c|c|c|}
\hline \multirow{2}{*}{ Entidad } & \multicolumn{7}{|c|}{ Ciclo } \\
\cline { 2 - 8 } & $2005-2006$ & $2006-2007$ & $2007-2008$ & $2008-2009$ & $2009-2010$ & $2010-2011$ & $2011-2012$ \\
\hline Cd. de México & 20235 & 23702 & 36194 & 40076 & 61584 & 78358 & 67620 \\
\hline Coahuila & 4851 & 5070 & 5275 & 5293 & 5314 & 4844 & 4614 \\
\hline Nuevo León & 4418 & 4495 & 4744 & 3954 & 3880 & 3294 & 4181 \\
\hline Oaxaca & 2396 & 2251 & 4057 & 5878 & 5610 & 5812 & 13519 \\
\hline Guerrero & 3603 & 4088 & 4032 & 4852 & 4132 & 4350 & 3881 \\
\hline Chiapas & 6310 & 8037 & 7742 & 6809 & 9401 & 9222 & 11027 \\
\hline
\end{tabular}

Fuente: Alcántara S. y Navarrete C., 2014.

${ }^{11}$ El Pronabes funciona bajo la coparticipación de los gobiernos estatales, los cuales apor$\tan 50 \%$ de los recursos, mientras que el resto lo aporta la Federación. El requisito para acceder a una beca del Pronabes es ser alumnos en una IES pública y provenir de una familia con ingreso inferior a tres salarios mínimos. La elección de los aspirantes se hace bajo el criterio de necesidad económica, se consideran prioritarios aquellos estudiantes que provienen de comunidades indígenas, rurales o urbano marginadas (Alcántara S. y Navarrete C., 2014). 
El cuadro muestra una tendencia creciente en la asignación de becas. En las entidades seleccionadas sobresalen Oaxaca y Chiapas, si se descuenta el efecto del tamaño de entidad para reducir el peso de la Ciudad de México. En otras palabras, aunque en términos absolutos la capital del país ha recibido mayor número de becas que el resto de entidades, en términos relativos son Oaxaca y Chiapas unas de las más beneficiadas por el tamaño de sus sistemas universitarios.

Aunque han surgido otros programas de acción afirmativa por parte de organismos no gubernamentales $(v \cdot g r$. el Programa de Apoyo a Estudiantes Indígenas en Instituciones de Educación Superior, PAEIIES, de la Ford-ANUIES y el Programa Universitario México Nación Multicultural Sistema de Becas para Estudiantes Indígenas, PUMC, de la UNAM), baste aquí la identificación del Pronabes como una acción de política central y visible en el horizonte de la interculturalidad promovida desde lo gubernamental.

En síntesis, el giro discursivo hacia la equidad educativa permeó en las acciones de política de los últimos años, promoviendo el diseño de dispositivos de atención a la desigualdad en las oportunidades de acceso a las IES. En este sentido se inscribe el creciente acceso de mujeres, personas con alguna discapacidad y grupos indígenas. Sin duda el paso de este discurso de la equidad hacia el establecimiento de las UI es pequeño. La creación de las UI recupera algo de este giro discursivo.

\section{El subsistema de universidades interculturales (UI)}

Hasta aquí queda referido el hecho de que los cambios en el marco normativo y la creación de programas compensatorios para el acceso y permanencia de estudiantes indígenas en ES formaron parte de un conjunto de acciones asociadas a una agenda de interculturalidad de creciente importancia en la esfera pública. En este horizonte cabría observar que las últimas décadas, y de forma particular a partir de 1992, los pueblos originarios en el continente venían rebasando las demandas del derecho a la tierra y al territorio, a sus lenguas y a sus culturas (Brysk, 2000), sumando a estas demandas el derecho a una educación cultural y lingüísticamente 
pertinente; es decir, una educación diversificada y apropiada para los contextos indígenas (Dietz, 2014b).

La educación indígena, bicultural, bilingüe o intercultural -por las distintas denominaciones y matices que ha tenido a través del tiempo- ha mostrado particulares rezagos de infraestructura y matrícula en la educación media superior y superior. Se trata de un rezago no solo expresado en la falta de IES públicas en las regiones indígenas del país, sino en cuanto a una oferta educativa apropiada a las necesidades, los valores, los saberes y las cosmovisiones indígenas (Dietz, 2014b). En este contexto, en el sexenio de Vicente Fox (2000-2006) se promovió la construcción de las denominadas universidades interculturales, dando así cumplimiento a uno de los objetivos definidos en el Plan Nacional de Educación (PNE, 2001-2006). El órgano creado ex profeso para este objetivo fue la ya referida Coordinación General de Educación Intercultural Bilingüe, un organismo dependiente de la SEP, cuya encomienda es, entre otras, crear y coordinar un subsistema de universidades interculturales (véase Acuerdo de creación en SEP, 2001). ${ }^{12}$

La construcción de las UI en los estados supuso el establecimiento de acuerdos entre la SEP, las autoridades educativas estatales, organizaciones indígenas y otras instituciones académicas locales (Schmelkes, 2009), además de gobernadores y presidentes municipales. ${ }^{13}$ El estatus jurídico de estas instituciones es el de

\footnotetext{
${ }^{12}$ La CGEIB fue creada por acuerdo del ejecutivo federal el 22 de enero 2001 como una instancia de la SEP encargada, entre otras tareas, de instalar un subsistema de educación superior intercultural, conforme con lo anunciado en sus promesas de campaña por el entonces candidato Vicente Fox (Didou A., 2014). De acuerdo con el Manual de procedimientos de la Coordinación (CGEIB, 2012), esta tiene como atribuciones fundamentales aquellas dispuestas en el artículo 16 del Reglamento Interior de la SEP que, entre otras, menciona: promover y evaluar la política educativa en materia de equidad, desarrollo intercultural y participación social, en todos los tipos y modalidades educativos; promover la colaboración de las entidades federativas y municipios, así como la de los diferentes sectores de la sociedad, pueblos y comunidades indígenas, en la realización de iniciativas orientadas a propiciar la equidad, el desarrollo intercultural y la participación social en todos los tipos, niveles y modalidades educativos; diseñar y establecer los mecanismos de supervisión y vigilancia tendientes al aseguramiento de la calidad y pertinencia de la educación que se imparta en el medio indígena, y asesorar y proponer los proyectos de normas y criterios para garantizar que los servicios educativos para toda la población, reconozcan la diversidad étnica, lingüística y cultural de la Nación, se eduque para el desarrollo intercultural, se fomenten los valores vinculados con la equidad y se propicie la participación social en todos los tipos, niveles y modalidades educativos, y otras (CGEIB, 2012).

${ }^{13}$ No se tiene información para valorar lo exhaustivas que fueron las consultas, o lo inclu-
} 
organismos descentralizados de los gobiernos de los estados (Mateos C. y Dietz, 2013) y su financiamiento es mixto; es decir, reciben recursos tanto de los gobiernos estatales como del federal.

Cabe insistir en que la inclusión de las UI dentro del PNE, 2001-2006 respondió, entre otras razones, a un contexto en el que -a decir de la propia CGEIB- distintos pueblos y organizaciones étnicas demandaban instituciones de educación superior cercanas geográfica y culturalmente a las comunidades (CGEIB, 2009. Citado en Mateos, 2013). En este trabajo se sostiene que las UI eran compatibles con la meta de que los jóvenes indígenas y otros de sectores sociales marginados tuvieran mayor acceso a la educación superior, de modo que la demanda de este nivel educativo por parte de los pueblos indígenas, en principio, no reñía con la política social del gobierno federal orientada a reducir los índices de marginación a través de la expansión de las oportunidades educativas, lo que facilitó su adopción por parte del gobierno federal. Además, como se verá en otro apartado, en el paradigma educativo que han seguido los gobiernos federales desde el sexenio de Carlos Salinas, la elevación de los niveles de estudio se ha visto como un instrumento para mejorar la competitividad y el desarrollo. Herederos de esta perspectiva, los gobiernos del PAN vieron en las UI un instrumento para mejorar los indicadores de desarrollo de los pueblos indígenas.

La primera UI oficial se construyó en el municipio de San Felipe del Progreso, en el Estado de México, que registra una alta presencia de población mazahua. La misión formal de la universidad es, según el decreto de creación referido por Felipe González, su primer rector, “...impartir programas educativos de alta calidad orientados a formar profesionales e intelectuales comprometidos con el desarrollo económico y cultural en los ámbitos comunitario, regional y nacional, cuyas actividades contribuyan a promover un proceso de revaloración y revitalización de las lenguas y culturas originarias, así como de los procesos de generación del conocimiento de estos pueblos" (González O.,

yentes que fueron los acuerdos para llevar las UI a las entidades. En prensa se tienen registrados casos en los que las dificultades para lograr acuerdos en torno a los municipios sede de las UI, terminaron bloqueando o, al menos, retrasando la instalación de las universidades (ver por ejemplo, Redacción, 2005). 
2007b: 256). Luego de esta primera unidad, la CGEIB gestionó la construcción de otras siete universidades.

Aunque el plan sexenal de Fox contemplaba la creación de 10 instituciones entre 2001 y 2006 (Didou A. y Remedi A., 2006), a la fecha la CGEIB ha creado solo ocho y ha reconocido u oficializado otras cuatro que se formaron desde iniciativas locales (ver Cuadro 1).

CUADRO 2. Ul adscritas a la CGEIB

\begin{tabular}{|c|c|c|c|c|c|}
\hline Denominación & \multicolumn{2}{|c|}{ Fecha de inicio } & Grupos étnicos & Municipios/Sedes & $\begin{array}{c}\text { Matrícula Ciclo } \\
\text { 2012-2013 }\end{array}$ \\
\hline $\begin{array}{l}\text { Universidad Autónoma Indígena de } \\
\text { México (Sinaloa) }\end{array}$ & Diciembre & 2001 & $s / d$ & $\begin{array}{l}\text { Mochicahui, los } \\
\text { Mochis y Choix }\end{array}$ & 2376 \\
\hline $\begin{array}{l}\text { Universidad Intercultural del Estado de } \\
\text { México (UIEM) }\end{array}$ & Diciembre & 2003 & $\begin{array}{c}\text { Mazahuas, otomíes, } \\
\text { tlahuicas, matlazincas } \\
\text { y nahuas }\end{array}$ & $\begin{array}{l}\text { San Felipe del } \\
\text { Progreso }\end{array}$ & 917 \\
\hline $\begin{array}{l}\text { Universidad Intercultural de Chiapas } \\
\text { (UNICH) }\end{array}$ & Diciembre & 2004 & $\begin{array}{l}\text { Tseltales, tsotsiles, } \\
\text { mames, zoques, choles y } \\
\text { tojolabales }\end{array}$ & $\begin{array}{l}\text { San Cristóbal de la } \\
\text { Casas }\end{array}$ & 1679 \\
\hline $\begin{array}{l}\text { Universidad Intercultural del Estado de } \\
\text { Puebla (UIEP) }\end{array}$ & Marzo & 2006 & $\begin{array}{l}\text { Tononacas, nahuas y } \\
\text { popolucas }\end{array}$ & Huehuetla & 214 \\
\hline $\begin{array}{l}\text { Universidad Intercultural Indígena de } \\
\text { Michoacán (UIIM) }\end{array}$ & Abril & 2006 & Purépechas & Pátzcuaro & 600 \\
\hline $\begin{array}{l}\text { Universidad Intercultural del Estado de } \\
\text { Tabasco (UIET) }\end{array}$ & Abril & 2006 & Choles y yokotanes & Oxolotán & 505 \\
\hline $\begin{array}{l}\text { Universidad Intercultural Maya de } \\
\text { Quintana Roo (UIMQRoo) }\end{array}$ & Octubre & 2006 & Mayas & José María Morelos & 631 \\
\hline $\begin{array}{l}\text { Universidad Intercultural del Estado de } \\
\text { Guerrero (UIEG) }\end{array}$ & Diciembre & 2006 & $\begin{array}{l}\text { Nahuas, tlapanecos y } \\
\text { mixtecos }\end{array}$ & La Ciénega & 350 \\
\hline $\begin{array}{l}\text { Universidad Intercultural de Nayarit } \\
\text { (UIN) }\end{array}$ & Septiembre & 2011 & $s / d$ & La Yesca & $s / d$ \\
\hline $\begin{array}{l}\text { Universidad Intercultural de San Luis } \\
\text { Potosí (UISLP) }\end{array}$ & Enero & 2011 & $s / d$ & $\begin{array}{l}\text { Cárdenas, Cerritos, } \\
\text { Ciudad Valles, Charcas, } \\
\text { Matehuala, Matlapa, } \\
\text { Tampacán, Tamuín, } \\
\text { Tamazunchale, } \\
\text { Tancanhuitz y Villa } \\
\text { de Reyes }\end{array}$ & 2387 \\
\hline $\begin{array}{l}\text { Universidad Intercultural del Estado de } \\
\text { Hidalgo (UICEH) }\end{array}$ & Octubre & 2012 & Otomíes & Tenango de Doria & 138 \\
\hline $\begin{array}{l}\text { Universidad Veracruzana Intercultural } \\
\text { (UVI) }\end{array}$ & $s / d$ & 2005 & $\begin{array}{c}\text { Totonacas, Nahuas, } \\
\text { Zapotecos, Mixes, Oto- } \\
\text { míes, Tepehuas, Zoques, } \\
\text { Popolucas, Zapotecosy } \\
\text { Chinantecos }\end{array}$ & $\begin{array}{l}\text { Ixhuatlán de Madero, } \\
\text { Tequila, Mecayapan } \\
\text { (Localidad de Hua- } \\
\text { zuntlán), y Espinal }\end{array}$ & $354^{*}$ \\
\hline & & & & Total & 10151 \\
\hline
\end{tabular}

Fuente: (Aguirre M., 2015; Mateos C. y Dietz, 2013; Schmelkes, 2009) y REDUI [http://www.redui.org.mx. Consulta 25 de junio de 2015]

* Matrícula que se esperaba en el 2014. 
Al conjunto de UI adscritas a la CGEIB u "oficiales" del Cuadro 1 , se debe agregar un conjunto de iniciativas de educación intercultural locales, promovidas por actores no gubernamentales, creadas al margen de la CGEIB y de los respectivos gobiernos estatales, aunque algunas han solicitado el reconocimiento oficial de sus estudios y otras son proyectos con dificultades para continuar en operación. Entre otras se pueden mencionar:

- El Instituto Superior Intercultural Ayuuk (en Oaxaca);

- La Universidad Intercultural de los Pueblos del Sur (UNISUR, en Guerrero).

- La Universidad Campesina e Indígena en Red (UCI-Red, en varios estados).

- La Universidad de la Tierra (en Chiapas y Oaxaca);

- La Escuela Normal Indígena Intercultural Bilingüe "Jacinto Canek" (Chiapas).

- Universidad Comunal del Cempoaltéptl (Oaxaca).

- Unidad de Estudios Superiores de Alotepec (Oaxaca).

Fuentes: (Mateos C. y Dietz, 2013; Schmelkes, 2009)

Sin pretensión de exhaustividad, este breve recuento de iniciativas oficiales y no oficiales en materia de educación intercultural hace visible el avance de la agenda del nivel superior de la educación intercultural en el país.

Según cifras referidas por Alcántara (2014), hacia 2011 se encontraban matriculados en las UI oficiales alrededor de 7 mil 500 estudiantes que, en conjunto, representaban aproximadamente el $0.90 \%$ del total de alumnos inscritos en educación superior del país (Alcántara S. y Navarrete C., 2014). Esto contrasta con los poco más de 10 mil alumnos que se estimaron en el ciclo 2012-2013 (ver Cuadro 1). Cifras más recientes de la CGEIB hablan de una matrícula total de 10962 estudiantes en el ciclo 2014-2015, de los cuales 46\% eran mujeres (PEEI, 2014-2018).

En su perspectiva formal, la creación de las UI se puede entender como una acción encaminada a diversificar la educación superior en términos lingüísticos, culturales y étnicos, además de descentralizarla y de regionalizarla (Dietz, 2014b). Formalmente no se trató solo de ampliar la cobertura, sino de generar un mode- 
lo universitario adaptado a los contextos rurales e indígenas con pertinencia cultural y lingüística, y que profesionalizara a jóvenes a fin de que contribuyeran en iniciativas socioculturales, asociativas, microempresariales y ambientales desde sus propias comunidades y regiones (Dietz, 2014b). Sin embargo, como se expone a continuación, la subsunción de las UI a una estrategia de política social limitó el significado y el alcance de la respuesta gubernamental frente a una agenda de interculturalidad cuya implicación de fondo rebasa la demanda educativa y la de programas sociales para el combate de la pobreza.

\section{LA POLÍTICA SOCIAL COMO MARCO DE LAS ACCIONES DE EDUCACIÓN INTERCULTURAL}

En el apartado anterior se ha hecho una revisión general de algunas acciones de política pública orientadas a la interculturalidad. Se han señalado diversas reformas al marco normativo encaminadas a detectar y superar formas de exclusión y de discriminación de los pueblos originarios. En el mismo tenor se multiplicaron los programas compensatorios en educación bajo un enfoque intercultural. ${ }^{14}$ Finalmente, la creación de las UI se planteó como la acción más visible y relevante en materia de interculturalidad.

En este apartado se problematiza el hecho de que algunas de las referidas acciones de política, específicamente las UI, estuvieron condicionadas o influidas - al menos bajo los gobiernos del PAN- por los criterios y el diseño de la política social vigente. Esta política está definida por dos factores: un paradigma desarrollista orientado al mercado exterior, y el combate a la pobreza como objetivo central, en detrimento de otros objetivos de política social. El primer elemento viene aparejado con el paradigma del capital humano, que encuentra un fuerte espacio de articulación con la política de educación superior. El segundo elemento se asocia con los programas compensatorios.

\footnotetext{
${ }^{14}$ No se pretende analizar ni evaluar en este trabajo la eficacia o los resultados de estas acciones.
} 


\section{El modelo de desarrollo hacia afuera y la política social}

Existe una asociación entre los modelos de desarrollo y la política social en América Latina (Franco, 2001). Así, por ejemplo, la llamada industrialización por sustitución de importaciones de mediados del siglo XX estuvo acompañada de una política social caracterizada por su vínculo con el mercado laboral, lo que planteaba como una estrategia central la seguridad social de los trabajadores. En contraste, a partir de la década de los ochenta la región experimentó un giro en el modelo de desarrollo, caracterizado por el énfasis en el mercado externo, lo que obligó a los gobiernos a adoptar el discurso y las estrategias de la competitividad y del progreso técnico para insertar a sus naciones en el mercado internacional. Fue bajo este paradigma de desarrollo que la política social comenzó a plantearse como una estrategia orientada a formar capital humano (ibid.). Esta nueva fase de desarrollo hacia afuera supuso la incorporación de la innovación tecnológica para lograr competitividad y enfrentar la competencia internacional. Algunos autores se refieren a esto como la integración de la política social a las necesidades del crecimiento económico (Ordóńez B., 2002). En este horizonte, también se podría plantear la integración de la política educativa a la política social, ya que a través de una triangulación, la política educativa termina subordinada a las necesidades de crecimiento económico a través de la generación de capital humano como recurso para incrementar la productividad.

En este contexto, la idea nacida en el marco de los llamados estados de bienestar, según la cual la política social era el instrumento mediante el que el Estado promovía los derechos sociales y redistribuía la riqueza y el ingreso por vía del gasto social, incluyendo en esto a sectores de la población históricamente excluidos, ha sido reemplazada por un paradigma de atención hacia las familias en situación de pobreza que, en los hechos, se ha traducido en prácticas asistencialistas (Jusidman, 2009). Algunos identifican esta fase con el tránsito de la política social salinista a la zedillista, cuando se introdujo el giro de política que apostó a las transferencias directas a los pobres (Cordera, 2008). 
En este contexto, en los últimos años ha ido madurando un paradigma de política social que fija sus criterios de intervención prioritaria de manera focalizada; es decir, identificando con la mayor precisión posible a los beneficiarios potenciales y diseñando programas con el objetivo de asegurar el impacto sobre el grupo seleccionado (Franco, 2001). Sobre esto se podría observar que el primer intento de focalizar la política social se planteó a través del Programa de Educación, Salud y Alimentación (PROGRESA) en el gobierno de Ernesto Zedillo (1994-2000). En este caso se buscaba atender a la población con mayor rezago en zonas rurales -y más específicamente a niños y madres-, mediante la dotación de un paquete básico de servicios de educación, salud y alimentación (Ordóñez B., 2002).

Se puede sostener que estas estrategias de intervención focalizada permearon en la política educativa como consecuencia de la asociación entre estas áreas de política. En otras palabras, la creación de un subsistema de universidades abocadas a proveer una educación cultural y lingüísticamente pertinente (i. e. una educación diversificada y apropiada para los contextos indígenas) evoca, en el fondo, una estrategia de intervención focalizada propia de la política social.

\section{La política social bajo Vicente Fox}

En algo que se planteó como el enfoque de la equidad y la igualdad, el Plan Nacional de Desarrollo 2001-2006 de Vicente Fox estableció un conjunto de decisiones y programas encaminados a mejorar el acceso a las pretendidas oportunidades de desarrollo entre la población (PND, 2001-2006). La instrumentación de este enfoque se tradujo en la creación de instituciones y programas regionales para poner al alcance de la población bienes y satisfactores básicos, entre los que se contaba la educación $(\mathrm{Ca}-$ sillas M. y Santini V., 2006).

Heredero del PROGRESA, el programa estelar de la política social de Fox, y que Felipe Calderón conservó, denominado Oportunidades, estuvo basado en el esquema de atención focalizada a los grupos en situación de pobreza o en situaciones de vulnerabilidad, sobre todo en el medio rural y a través, esencialmente, 


\title{
de transferencias monetarias (Jusidman, 2009). Del Programa Oportunidades Jusidman dice:
}

\begin{abstract}
Se trata de programas masivos y poco complejos, elaborados sobre la base de una interpretación de la pobreza centrada en las carencias individuales, tanto materiales como de capacidades, y orientados a la calificación para la inserción en el mercado de trabajo. No contemplan la participación de la población en su diseño, ejecución o evaluación. De manera marginal y complementaria, se acompańan de programas para la construcción de infraestructura social y de mejoramiento de la vivienda. Tampoco incluyen una estrategia paralela de desarrollo de oportunidades de tipo productivo. No construyen ciudadanía, no desarrollan participación, ni responsabilidad, ni solidaridad. Este tipo de planes tiende a generar dependencia y a destruir la iniciativa, a fomentar el individualismo y a afectar el tejido social en las comunidades. Son programas de enorme alcance pero de pobre concepción frente a la complejidad de la problemática social del país (Jusidman, 2009: 204).
\end{abstract}

La política educativa del foxismo, y específicamente aquella orientada a la población indígena, parece una extensión de la política social que en esos años se planteó el reconocimiento de la igualdad de derechos y de oportunidades de la población para participar de los beneficios del desarrollo y para acceder a los servicios de bienestar social. Un instrumento clave para esto último se identificó en la educación (Didou A. y Remedi A., 2006).

Por otro lado, la vinculación de la política social a una estrategia de desarrollo hacia afuera y a una lógica de combate a la pobreza incentivó las metas de la política educativa, específicamente las relativas a la expansión del sistema universitario y a la formación de capital humano. En este sentido, se sugiere que en los últimos ańos la política social y la de educación superior generaron un área de convergencia en torno a la meta de lograr un acceso creciente al sistema universitario, especialmente entre aquellos jóvenes de sectores vulnerables, como una suerte de diseño focalizado, el mismo que se seguía en la política social. ${ }^{15} \mathrm{El}$ incremento

\footnotetext{
${ }^{15}$ En 1997 la SEP definió un conjunto de lineamientos para promover de forma ordenada la ampliación de la oferta educativa. Esta debía surgir de las iniciativas de los gobiernos de los estados y estar sustentada en estudios avalados técnicamente por las Comisiones estatales para la planeación de la educación superior (Coepes) (Rubio O., 2006).
} 
de la oferta y de la matrícula de estudiantes en educación superior tendría que redundar en una mayor disponibilidad de capital humano y en una mejora de la productividad que el modelo de desarrollo hacia afuera demandaba. La creación de las UI era, en la percepción del gobierno foxista, compatible con las metas senaladas, además de que atendía una demanda creciente entre grupos organizados de los pueblos originarios: educación superior.

La asociación de la política educativa con la política social terminó identificando $-y$ reduciendo- la primera con la lucha contra la pobreza. En este binomio, la educación se vuelve un instrumento. Por ello el trabajo plantea la existencia de un reduccionismo o una desproporción de origen entre la respuesta gubernamental y la agenda de interculturalidad, que no puede reducirse ni a una agenda educativa, ni a una agenda social, aunque no las excluya.

$\mathrm{Al}$ responder con la creación de un subsistema de UI, que en el fondo buscaba mejorar el acceso de los jóvenes indígenas a las Instituciones de Educación Superior (IES), incrementar sus oportunidades de inserción en el mercado laboral y abatir con ello los índices de marginación, se reducía la construcción de un sistema de relaciones sociales pluricultural o la reconfiguración del viejo Estado-nación, objetivo central de algunos grupos impulsores de la agenda intercultural.

Esta debilidad estructural inicial de las UI oficiales no niega los esfuerzos que desde la misma CGEIB y desde las propias comunidades universitarias se realizan para reapropiarse de este proyecto y construir modelos o propuestas de interculturalidad que buscan sobrepasar los límites del enfoque gubernamental inicial. ${ }^{16}$

\section{EL PARADIGMA DEL CAPITAL HUMANO}

Hasta aquí queda dicho que en los últimos años se multiplicaron las acciones de política pública orientadas a los grupos étnicos del país, y de manera muy visible aquellas abocadas a dar acceso a ser-

\footnotetext{
${ }^{16}$ Futuras investigaciones deben indagar la existencia de procesos de apropiación al interior de las propias UI; es decir, indagar si acaso lo que inició como un proyecto gubernamental sesgado por la política social, ha terminado generando en el nivel de las comunidades universitarias procesos de construcción de interculturalidades que acaso tiendan a sobreponerse a las reducciones que marcaron su inicio desde la acción oficial.
} 
vicios de educación superior. No obstante, se puede sostener que en el caso específico de las UI, la lógica detrás de su creación parece fuertemente condicionada por las estrategias de política social; de tal manera que, a pesar de su aparente novedad, en realidad las UI no supusieron ninguna ruptura con las metas planteadas por los gobiernos federales, lo que refuerza la idea de que las acciones emprendidas no representan un proceso sustancial de configuración social y política que avance hacia un Estado pluricultural, objeto central en la agenda de la interculturalidad.

En este apartado se agrega un elemento más que refuerza el argumento de que el subsistema de UI fue menos rupturista de lo que podría suponerse, ya que no solo reforzaba las metas de combate a la pobreza al ampliar el acceso a la ES, sino que además se inscribía en el modelo educativo impulsado por el gobierno federal desde los años noventa, y una de cuyas estrategias era la formación de capital humano como instrumento para el desarrollo.

Los noventa se identifican como una década de reformas significativas en ES en México, lo que supuso, entre otras cosas, un cambio en el rol y en los recursos gubernamentales orientados a regular el sistema universitario del país. Kent resume bien estos cambios: introducción de la planeación estratégica, un sistema de acreditación de licenciaturas, expansión de las universidades tecnológicas, expansión de los institutos tecnológicos estatales, expansión del posgrado nacional, expansión del sector privado, entre otros (Kent S., 2009). Los cambios han sido vertiginosos. De esta manera, las UI surgen en un contexto en el que se ha pretendido "...ir estableciendo un Estado evaluador y vigilante del destino de los recursos públicos que se canalizan a las universidades, y de asumir -en suma- un papel proactivo y más directivo en materia de educación superior" (ibid.: 40).

\section{El paradigma del capital humano llevado a la educación superior}

La teoría del capital humano tiene su origen en la economía neoclásica (Beaud y Dostaler, 2005). ${ }^{17}$ Según esta teoría, los re-

\footnotetext{
${ }^{17} \mathrm{La}$ expresión capital humano apareció por primera vez en el título de un artículo que publicó Jacob Mincer en 1958; de modo que este autor es considerado como el iniciador,
} 
cursos humanos son también considerados como capital, y administrados según los mismos principios que los recursos físicos. En un trabajo cuya primera edición apareció en 1964, Gary Becker (1993) planteó que la escolarización, la capacitación, la atención médica y la promoción de buenos hábitos también eran formas de capital en las que se podía invertir, aunque lo que se producía con ello era capital humano, no físico o financiero. En el mismo trabajo el autor señalaba la existencia de una asociación entre inversión en capital humano e incremento en los ingresos de las personas.

Los desarrollos posteriores en la teoría del capital humano han llegado a sugerir que la pobreza resulta del hecho de que las personas no han adquirido las habilidades cognitivas básicas para insertarse en los mercados laborales. De modo que sería necesario darles acceso a la escuela o darles recursos cognitivos para sacarles de la marginación (Bazdresch P., 2001). ${ }^{18}$

Hacia finales de los noventa la Comisión Internacional sobre Educación, Equidad y Competitividad Económica en América Latina y el Caribe, creada en el seno del Programa de Promoción de la Reforma Educativa en América Latina y el Caribe (PREAL), rindió un informe en el que se señalaba una serie de directrices encaminadas a promover la calidad y el desarrollo de la educación en la región. Con estas se esperaba mejorar la situación de desigualdad, pobreza, exclusión y competitividad regional (Aponte H., 2008). El dato relevante es que este informe promovía un paradigma que ligaba la educación al desarrollo y al crecimiento económico. En el mismo sentido, la UNESCO y otros organismos internacionales difundieron, durante los noventa, la idea de que sin más y mejor educación superior, los países en desarrollo tendrían mayores dificultades para beneficiarse de la economía global basada en el conocimiento (Alcántara, 2013). De esta manera, en los últimos años se ha fortalecido un paradigma educativo que, en el fondo, supone que mayor educación genera mayor productividad de la fuerza de trabajo, y en consecuencia, mayores

aunque la primera presentación como tal de la teoría se atribuye a un artículo de 1961 de Theodore W. Schultz (Beaud y Dostaler, 2005).

${ }^{18}$ Algunos autores argumentan que si bien no se puede demostrar que la educación permite superar el umbral de pobreza, tampoco se ha demostrado que se pueda prescindir de la educación en el combate contra la pobreza (Bazdresch P., 2001; Kent S., 2009). 
ingresos potenciales para los trabajadores (Bazdresch P., 2001). Además, sugiere que los sistemas educativos cumplen una función distributiva al preparar para los diferentes roles de la división social del trabajo y al asignar el talento de manera eficiente con base en la competencia de los más hábiles (ibid.).

Para un gobierno que busca mejorar sus indicadores de acceso a la educación superior, en el entendido de que estos se traducirán en una mejora en la formación del capital humano y en la reducción de la pobreza, la construcción de universidades que ofrezcan servicios educativos culturalmente pertinentes resulta una estrategia que no contrasta con esta lógica; antes bien, la secunda. De esta manera, se insiste en que la creación de las UI no contradecía las metas de la política social ni las de educación superior, ni la estrategia de desarrollo seguida desde los noventa. A esta convergencia de factores se agregó el avance de la agenda de interculturalidad promovida por actores etnopolíticos, apuntalada a partir de 1994 por la irrupción del Ejército Zapatista de Liberación Nacional (EZLN) en el estado de Chiapas.

En el horizonte aquí planteado se debe agregar que la reducción de la educación intercultural a una estrategia de política social y a una estrategia de expansión de matrícula y de formación de capital humano sí entró en contradicción con la agenda de interculturalidad de algunos actores locales, lo que de hecho les ha permitido reforzar sus discursos y sus estrategias de construcción y movilización al margen de la acción gubernamental (Alonso G., Hernández A., y Solís C., 2014; Dietz, 2009; González A., 2009; Lehmann, 2013; López, 2009; Pérez R., 2009; Von Groll, Keyser O., y Silva C., 2013). Oaxaca y Chiapas son, al respecto, casos emblemáticos, por la multiplicidad de proyectos y de agendas de interculturalidad al margen de lo gubernamental, o en diálogo crítico y conflictivo con este último. ${ }^{19}$

\footnotetext{
${ }^{19}$ Para un acercamiento a este conjunto de experiencias se puede revisar (Baronnet, 2009, 2010; Meyer y Maldonado A., 2004).
} 


\section{LA AGENDA INTERCULTURAL COMO CONTEXTO DE LAS POLÍTICAS}

Tal como se planteó en la introducción de este trabajo, se quiere sostener la idea de que las UI surgieron en el espacio de convergencia que formaron la política social y la de educación superior ya referidas, y la agenda de interculturalidad promovida en los últimos años por una coalición de actores etnopolíticos abocados a avanzar en el reconocimiento de un conjunto de derechos identitarios y hacia la interculturalización de la sociedad. Visualmente esta idea se puede proponer en la gráfica 1.

\section{GRÁFICA 1. Las UI como centro de convergencia entre tres factores}

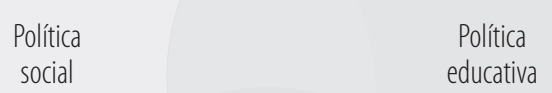

Ulc's

Agenda

intercultural

Fuente: Elaboración propia

De esta manera, a pesar de que las UI oficiales se crearon durante los gobiernos del PAN, hay elementos cuyo desarrollo precede a este subsistema universitario. En el segundo y tercer apartados se abordaron la política social y la política educativa, respectivamente. En este se ofrece una aproximación a la agenda 
intercultural para completar la ecuación que, a juicio del autor, se configuró para dar pie a las UI.

\section{Fortalecimiento del movimiento indígena y la agenda intercultural}

No obstante su heterogeneidad interna, la agenda de interculturalidad había venido dando pasos importantes a través del movimiento indígena desde los ańos setenta (Sarmiento S., 1985), aunque de manera más consistente durante la década de los noventa, en favor de reivindicaciones y demandas identitarias que han estado tomado cuerpo en las reformas constitucionales que reconocieron la composición pluricultural de México. En este sentido, la reforma al Art. $4^{\circ}$ en 1992 -y su modificación como Art. $2^{\circ}$ en el 2001- colocó al gobierno mexicano dentro de una tendencia normativa que, en el plano internacional, ha ido otorgando mayor espacio a los derechos de los pueblos indígenas (Sieder, 2002a). Los instrumentos más claros en este sentido son el Convenio 169 de la Organización Internacional del Trabajo (OIT) de 1989, ratificado por México en 1991 y, más recientemente, la Declaración de las Naciones Unidas sobre los Derechos de los Pueblos Indígenas (2007).

Las reformas constitucionales de los noventa se tradujeron en la asunción de México como una nación pluricultural, y esto introdujo un elemento nuevo en los programas de desarrollo. Sin embargo, los gobiernos federal y estatales vienen de un largo y reiterado fracaso en las políticas de atención a la diversidad, como lo demuestran las cifras actuales del rezago del subsistema de educación indígena (INEE, 2014). A esta prolongada y reiterada incapacidad gubernamental, se agregó una agenda nueva de derechos y de demandas orientadas a la atención de los pueblos originarios, incluyendo la de proveer servicios educativos a nivel superior.

El desarrollo del marco normativo internacional en materia de derechos identitarios ha sido resultado y a la vez factor condicionante del movimiento indígena. Para dar cuenta de esto baste recordar que desde 1975 se conformó el Consejo Mundial de Pueblos Indígenas (CMPI). En su creación participaron 52 delegados y 135 observadores provenientes de diecinueve países 
(Ramírez B., 2014). El naciente CMPI gozó del estatus de organización no gubernamental (ONG) en el seno de la ONU, que en 1982 decidió crear el Grupo de Trabajo sobre Poblaciones Indígenas, en el marco de la Subcomisión sobre la Prevención de la Discriminación y la Protección de Minorías. De esta manera, el movimiento indígena adscrito al Consejo devino un interlocutor permanente al interior de la ONU, lo que ha tenido efectos claros en el desarrollo del marco jurídico internacional (Ramírez B., 2014).

Sin pretender ver en el movimiento indígena un proceso lineal y sin contradicciones $-\mathrm{y}$ sin el objetivo de detallar aquí su desarrollo-, se puede observar con la literatura especializada que en los últimos treinta años han surgido múltiples movimientos sociales y políticos en América Latina, demandando el reconocimiento de los derechos fundamentales de los pueblos, a grado tal que algunos consideran que la región se ha convertido en punta de lanza de esta lucha (Castellino y Walsh, 2004; Morgan, 2004; Sieder, 2002b).

El fortalecimiento del movimiento indígena en América Latina se vio favorecido también por la etapa de transiciones desde los gobiernos autoritarios durante los años 80-90 (Sieder, 2002a), y por las conquistas logradas por los movimientos promotores de los derechos humanos, en cuya agenda terminó incluyéndose la demanda de respeto a los derechos de los pueblos indígenas (Casillas M. y Santini V., 2006).

El movimiento indígena ha tenido su propio correlato en México. Sarmiento (1985), uno de los estudiosos del tema, refiere que entre 1970 y 1985 hubo un desarrollo cuantitativo y cualitativo de los movimientos indígenas que se expresó en el surgimiento de múltiples y mejores formas organizativas. Además se plantea que, a pesar del corporativismo que permeó en las organizaciones indígenas y campesinas desde los años cuarenta, es posible documentar pasajes de luchas reivindicatorias que en el largo plazo mantuvieron la presencia de los actores indígenas en el sistema político (López B., 2005).

Durante los ochenta las demandas del movimiento indígena mexicano se vieron agravadas por las constantes denuncias de explotación y de exclusiones económico-sociales y culturales a las comunidades. A esto se sumó que las reiteradas crisis económicas habían reducido el gasto social de esa década (Sarmiento S., 1985). 
En síntesis, hay un nuevo papel de la etnicidad en los debates y en las políticas, generado en el contexto de emergencia del movimiento indígena durante las últimas décadas. Este ha interactuado a su vez con un marco normativo internacional que en los últimos años caracterizó los derechos de los pueblos indígenas como derechos humanos y de grupo..$^{20}$ Este conjunto incidió en las reformas constitucionales que reconocieron las composiciones pluriculturales y pluriétnicas de las sociedades latinoamericanas en la década de los noventa (Sieder, 2002a), y que ya se mencionó para el caso de México (vid. Supra). En tal sentido, se puede proponer que el movimiento indígena y el marco de los derechos han coevolucionado, y que en conjunto han generado un clima político y social que redistribuyó recursos de negociación $(v \cdot g r$ la atención pública y gubernamental) y que empoderó sectores que, en este contexto, no solo han demandado, sino que han encabezado proyectos emergentes.

Al dinamismo observado se sumó la ya referida irrupción del EZLN, un movimiento indígena y armado que capitalizó el contexto político y jurídico de principios de los noventa y que a la vez abonó en este clima que poco a poco había venido favoreciendo la atención de la agenda intercultural.

\section{Lo intercultural como agenda y concepto problemático}

No es fácil resumir los contenidos de esto que en el cuerpo del documento se ha planteado en singular como la agenda de la interculturalidad impulsada por el movimiento indígena. Y no lo es especialmente porque se trata de un cuerpo de demandas, proyectos y actores heterogéneo, que desde el horizonte de la etnicidad busca trasladar sus demandas a la esfera pública y, en algunos casos, generar respuestas gubernamentales, mientras que en otros se busca, justamente, distanciarse de esa esfera, alentando una relación conflictiva (Pérez R., 2009).

Un hecho que dificulta también la definición de la agenda intercultural es la fuerte disputa en torno a su concepto (Dietz,

\footnotetext{
${ }^{20}$ Los derechos de grupo resultan una concepción de los derechos que desafía la vieja concepción liberal para la que solo se concibe al individuo como el depositario de derechos (v. gr. Vitale, 2004).
} 
2012). Al respecto Boccara propone, precisamente, una perspectiva de la interculturalidad como conflicto, como "proyecto político-cultural en construcción”, "tensionado", "contingente" y "lleno de contradicciones", "que se despliega a través de nuevas luchas de poder" (2012: 13).

Dietz y Mateos advierten, incluso, que la polisemia del término "intercultural" entraña un "riesgo programático y práctico" que se traduce en una "nueva ideología hegemónica" que guarda una "vaguedad conceptual" y que importa y mimetiza soluciones "supuestamente interculturales" que son "inoperables, contraproducentes o nocivas" (2011: 15). De esta forma, se menciona que la interculturalización ha entrado en una fase de ambigüedad, no solo en su definición, sino en su construcción; de modo que, si bien el movimiento indígena se ha coordinado en torno a la demanda de políticas de reconocimiento y de los derechos humanos, en la base o en el nivel local se genera un abanico de interculturalidades en construcción y en contradicción frente a las que lo gubernamental aparece con distintos significados y con distintas respuestas (v.gr. López, 2009; Viaña, Tapia y Walsh, 2010).

Dentro de esta agenda compleja (y disputada) ha tomado un lugar central el componente educativo, o de la educación intercultural. Al respecto, algunos hablan de "mediaciones étnicas" para referirse a la participación de algunos agentes en la construcción de los proyectos de educación intercultural (González A., 2009). En este sentido, bien se podría hablar de agendas étnicas que han inyectado un fuerte dinamismo en el sistema de educación superior y que hacen eco de procesos nacionales e internacionales que presionan hacia el cambio. En este punto bien se puede señalar una "coyuntura nacional-global" que empuja hacia la "redefinición del pacto social" (ibid.).

En el tema de la educación, algunos trabajos han documentado la existencia de interculturalidades descolonizadoras, según las cuales, lo educativo tendría que avanzar como un proyecto pedagógico-político (político en cuanto proyecto contra el orden de relaciones de poder existentes) que se oponga a los enfoques homogeneizadores, que transforme las relaciones sociales y culturales y construya una ciudadanía equitativa (Von Groll et al., 2013). 
En el mismo sentido, se puede identificar una agenda que busca la interculturalización de las mayorías; es decir, en el que no se trata de trabajar solo proyectos de interculturalidad con las minorías, sino también de educar a las mayorías con el fin de modificar los términos del pacto social (Mateos C. et al., 2013).

Un hecho que no debe omitirse es que la conformación y la disputa por la agenda intercultural en la región está condicionada por la existencia de graves asimetrías y desigualdades (económicas, políticas y culturales), de suerte que con frecuencia las posturas interculturalistas se empatan con posturas que no solo reivindican derechos identitarios y culturales, sino la superación de esas asimetrías, lo que supondría una verdadera reconfiguración de las relaciones sociales.

Se ha documentado también una propuesta de interculturalidad como ética de la convivencia que desmonta el etnocentrismo y las fronteras identitarias (Pérez R., 2009). En esta perspectiva pueden referirse tres aspectos en los que no todos los actores que promueven la interculturalidad están de acuerdo: “...la necesaria ruptura de las fronteras identitarias... la promoción de la hibridación cultural e identitaria, que conduce a la integración de nuevas identidades, y... la ruptura con los esencialismos culturales e identitarios (ibid.: 225). La interculturalidad como ética de la convivencia llevaría a desdibujar identidades y culturas frenando la construcción de nuevos etnocentrismos y de nuevas exclusiones.

En este horizonte conceptual y de proyectos tan diversos $-y$ que en estos párrafos apenas queda esbozado-, no es difícil entender que el subsistema de UI creado por el gobierno federal resulta una propuesta reducida. En sentido estricto, estas universidades terminan ampliando la oferta educativa, tratando de hacerla cultural y socialmente pertinente, pero no está claro cómo contribuirían en la reconfiguración de las relaciones sociales y en una superación de las asimetrías basadas en la etnicidad que han caracterizado a la sociedad mexicana hasta hoy. 


\section{Tensiones entre la agenda intercultural y la política social}

La política social se ha centrado cada vez más en el combate a la pobreza. La agenda intercultural busca modificar las relaciones entre la sociedad y los poderes públicos visibilizando las adscripciones étnicas.

El viejo proyecto de Estado-nación promovió la construcción de una identidad nacional, con lo que ocultó la diversidad social y cultural del país. En este proyecto no había cabida para la diversidad y la diferencia cultural. Además de que se conformó un sistema educativo ad hoc abocado a la difusión de una identidad nacional y de unos valores afines.

El debate sobre la educación intercultural se nutre del discurso de los derechos. Este último ha puesto en el centro de la discusión el problema de los derechos de las minorías. Esta perspectiva avanza después hacia el problema de la naturaleza y organización del Estado (Vitale, 2004), y en esta perspectiva se discute que el modelo de Estado-nación no es una formación natural, sino una creación humana que encarna un orden en el que una identidad nacional subsume al resto de las identidades. En tal sentido, la interculturalización de las universidades resulta un esfuerzo que desafía los diseños institucionales de dicho Estado y de su sistema educativo (Dietz, 2009).

La educación intercultural va más allá de la política educativa. Supone un rediseño institucional del viejo Estado-nación; lo que implica la asunción de ciertas nociones antropológicas y pedagógicas que contribuyan en la administración de la diversidad.

Algunos autores (Mateos C. y Dietz, 2013) refieren que las sociedades contemporáneas atraviesan por procesos constitutivos, de diferenciación y de integración. En el fondo se trata de una redefinición de las relaciones entre el Estado y las sociedades, algo que evoca en sí el problema de las nuevas formas de ciudadanía. Por eso aquí se insiste en que la educación intercultural implica un desafío mucho más complejo que el de ciertas acciones de política educativa. Supone encontrar una solución a la administración de la diversidad y con ello a la inclusión de distintas identidades en el seno de un mismo Estado. Se trata, en definitiva, del rediseño del Estado-nación prescindiendo de la 
construcción de una identidad nacional. Y quizá los trabajos de la CGEIB y de las propias comunidades universitarias en el seno de las UI estén avanzando hacia allá en lo que podría ser una fase de reapropiación de las UI desde lo local, de modo que, superando su adscripción a las metas de la política social y a las metas de expansión de la matrícula universitaria en zonas rurales e indígenas, podría generarse con el tiempo una propuesta que contribuya en un proyecto de interculturalidad de más largo alcance.

\section{REFLEXIONES FINALES}

En los apartados previos queda esbozado el hecho de que las acciones de política pública orientadas a la interculturalidad son una respuesta reducida frente a la compleja agenda señalada. En particular se sugiere que la política social y la política educativa constrińen los alcances de los cursos de acción gubernamental frente a una serie de reclamos interculturalistas más cercanos a la exigencia de reconfiguración de la sociedad, la política y el Estado, según se deduciría del artículo $2^{\circ}$ constitucional.

Una idea esbozada en el cuerpo del trabajo es que las acciones de política enunciadas en el primer apartado (vid. Supra) no han logrado constituirse en una política de interculturalidad. Las acciones son piezas sueltas de cursos de acción gubernamental desarticulados y que abarcan áreas como la política social, las políticas antidiscriminatorias, las políticas educativas, las políticas de desarrollo, las reformas legislativas, la construcción de UI, etc. Es verdad que se podría discutir si las disposiciones del Art. $2^{\circ}$ en realidad son susceptibles de dar pie a algo denominado política de interculturalidad, y a qué estaría abocada una política tal. $\mathrm{O}$ por el contrario, si la interculturalidad es de una naturaleza transversal tal que está condenada a ocupar pequeños apartados en múltiples políticas, como hasta ahora ha sucedido.

Algunas lecturas optimistas en torno a las UI ven en estas un elemento útil de atención al fenómeno de la exclusión social y de la diversidad cultural (Casillas M., 2012). En el mismo sentido se vería en estas instituciones un esfuerzo en positivo para desarrollar una propuesta educativa culturalmente pertinente, con arraigo social y compromiso comunitario, que pretenderían formar 
comunidades académicas que recuperen conocimientos, saberes y valores propios de las culturas del país y que entablen un diálogo con el conocimiento científico (ibid.). Esta perspectiva optimista permite destacar el hecho de que las acciones de política desarrolladas en los últimos años dialogan en distintos términos con la heterogeneidad de actores interculturales; de modo que en algunos casos las posturas frente a las UI tienden a la asimilación o adhesión optimista, mientras que en otros tienden al distanciamiento crítico (Alonso G. et al., 2014; López, 2009; Pérez R., 2009; Viańa et al., 2010).

El distanciamiento crítico frente al subsistema de UI se ve reforzado por la cercanía estructural que estas instituciones tuvieron, en su origen, con las metas de política social y de política educativa en las que se fijaron metas cuantitativas de acceso al sistema universitario en detrimento de objetivos cualitativos de construcción de un modelo de interculturalidad; y en el extremo, por los objetivos del sistema de educación superior de articular la oferta educativa con el mercado; objetivos que, en última instancia, no se han cumplido, pues como dice Cordera (2008), los programas han mejorado los niveles promedio de educación, pero la economía no genera empleos, con lo que las expectativas puestas en la educación superior terminan no cumplidas .

Las acciones de política de los últimos años entran en contradicción con una interculturalidad que no mira en la educación superior un instrumento de desarrollo económico o de formación de capital humano sino, al menos en algunas de sus vertientes más críticas y contestatarias, uno para horizontalizar las relaciones sociales y modificar las relaciones de los grupos étnicos con el Estado. En otras palabras, la educación intercultural en algunas de sus vertientes se vuelve parte de un proyecto político amplio que propone una reconfiguración del Estado-nación, de la democracia, de los derechos, de la ciudadanía, etc., y esto está más allá de la respuesta gubernamental hasta ahora ejecutada, de modo que esta tensión abre un campo de proyectos interculturales al margen o en relación crítica con lo gubernamental.

La política social en los últimos años se ha planteado la atención de distintos problemas de exclusión social. De manera paralela, la política intercultural tendría que establecer tareas de 
inclusión para solventar aquellas exclusiones basadas en la diversidad cultural y étnica. Hay una frontera mínima entre las exclusiones/inclusiones que atañen a la política social y a una posible política de interculturalidad, pero no verla, ha llevado a asimilar las acciones de política intercultural a las de política social.

Por otro lado, las políticas de educación superior manifiestan propósitos relativos a la cobertura, la calidad, la pertinencia, la diversificación, la descentralización, la equidad, entre otras (Rubio O., 2006). El cumplimiento y alcance de dichos propósitos, contrario a la percepción del mismo Rubio, tendrían que problematizarse, especialmente si se trata del asunto de la pertinencia, luego que, en los hechos, las UI muestran dificultades en torno a su diseño, organización y conformación de un modelo de interculturalidad (González O., 2004; González O., 2007b).

Cuando se contrasta a las UI con la agenda intercultural como proyecto político emergente, la correspondencia se pierde. Las UI son arenas de construcción de interculturalidad o de tensión entre proyectos o concepciones de esta. Sin poder profundizar en los procesos o casos específicos, baste decir que hay tensiones entre la oferta gubernamental de interculturalidad y al interior de las UI, y de estas con la agenda de interculturalidad de otros actores emergentes.

En resumen, las dificultades para definir una agenda y un concepto de interculturalidad unitarios plantea un escenario problemático para la interacción y la coordinación de los actores en la esfera pública. La heterogeneidad o la existencia de múltiples proyectos de interculturalidad en el ámbito local plantean límites en la acción gubernamental.

\section{REFERENCIAS BIBLIOGRÁFICAS}

Aguirre M., M. "Comunidades de aprendizaje: retos para la ampliación del impacto social de las Universidades Interculturales", en Documento de Trabajo, núm. 186, México, Centro de Estudios Sociales y de Opinión Pública, 2015. Ahuja S., R., Berumen C., G., Casillas M., M. L., y Crispín B., M. L. Politicas y fundamentos de la educación intercultural 
bilingüe en México, México, SEP, Coordinación General de Educación Intercultural y Bilingue, Comisión Nacional para el Desarrollo de los Pueblos Indígenas, 2004.

Alcántara, A. "Educación superior e inclusión social en México: algunas experiencias recientes", en Universidades, vol. 63 núm. 57, México, UDUAL, 2013, pp. 17-28.

Alcántara S., A., y Navarrete C., Z. "Inclusión, equidad y cohesión social en las políticas de educación superior en México", en Revista Mexicana de Investigación Educativa, México, COMIE, vol. 19, núm. 60, 2014, pp. 213-239.

Alonso G., L., Hernández A., V. M., y Solís C. E. "La universidad intercultural de los pueblos del sur. Una opción de educación no formal para la población indígena en el estado de Guerrero, México", en Revista Mexicana de Investigación Educativa, Mexico, COMIE, vol. 19, núm. 60, 2014, pp. 103-128.

Aponte H., E. "Desigualdad, inclusión y equidad en la educación superior en América Latina y el Caribe: tendencias y escenario alternativo en el horizonte 2021", en A. L. Gazzola y A. Didriksson (Eds.), Tendencias de la educación superior en América Latina y el Caribe, Caracas, IESALC-UNESCO, 2008, pp. 113-154.

Baronnet, B. Autonomía y educación indígena: las escuelas zapatistas de las cañadas de la selva lacandona de Chiapas, México, México, COLMEX, 2009.

Baronnet, B. "Zapatismo y educación autónoma: de la rebelión a la dignidad indígena”, en Sociedade e Cultura, Brasil, Universidade Federal de Goiás, 2010.

Bastiani G., J. y Moguel V. R. "Exclusión e inclusión en el modelo de educación superior intercultural: el caso de la Universidad Intercultural de Chiapas", en Signos Lingüisticos, México, UAM, núms. 12-13, 2010, pp. 23-56.

Bazdresch P., M. "Educación y pobreza: una relación conflictiva", en A. Ziccardi (Ed.), Pobreza, desigualdad social y ciudadania: los limites de las politicas sociales en América Latina, Buenos Aires, Consejo Latinoamericano de Ciencias Sociales, 2001, pp. 65-81. 
Beaud, M., y Dostaler, G. Economic thought since Keynes: a history and dictionary of major economists, USA, Routledge, 2005.

Becker, G. S. Human capital: A theoretical and empirical analysis, with special reference to education (3a ed.), USA, University of Chicago Press, 1993.

Bertely B., M. "Educación superior intercultural en México", en Perfiles Educativos, núm. 33, México, UNAM, 2011, pp. 66-77.

Bertely B., M., Dietz, G., y Díaz T., M. G. Multiculturalismo y educación, 2002-2011, México, ANUIES, 2013.

Boccara, G. "La interculturalidad como campo social", en Cuadernos Interculturales, Viña del Mar, Chile, Universidad de Playa Ancha, vol. 10, núm. 18, 2012, pp. 11-30.

Brysk, A. From tribal village to global village: Indian rights and international relations in Latin America, Stanford, California, Stanford University Press, 2000.

Casillas M., M. L. "Políticas públicas de atención a la diversidad cultural y lingüística, en la educación superior en México", en M. A. Casillas A., J. Badillo y V. Ortiz M. (Eds.), Educación superior para los pueblos indigenas y afrodescendientes en América Latina. Contextos, politicas y experiencias escolares, México, Dirección General del Área Académica de Humanidades, Universidad Veracruzana, 2012, pp. 21-42.

Casillas M., M. L., y Santini V., L. Universidad Intercultural. Modelo Educativo, SEP, Coordinación General de Educación Intercultural y Bilingüe, 2006.

Castellino, J., y Walsh, N. International Law and Indigenous Peoples, Leiden, Martinus Nijhoff, 2004.

Castro G., M. Politica social y pueblos indígenas: un análisis desde la participación y organización social, México, Universidad Autónoma del Estado de Hidalgo, Instituto de Ciencias Sociales y Humanidades, 2009.

Castro R., J. "La Universidad Indígena Intercultural de Michoacán: ideas para una universidad diferente", $\mathrm{Ra} X i$ mhai, México, Universidad Autónoma Indígena de México, vol. 1, núm. 3, 2005, pp. 635-642.

CDI. Instituto Nacional Indigenista. Comisión Nacional para el Desarrollo de los Pueblos Indígenas, 1948-2012, México, 
CDI, 2012. Disponible en http//www.cdi.gob.mx. Fecha de acceso, julio de 2015.

CGEIB. Declaración de Pátzcuaro sobre educación superior intercultural, en Tercer Encuentro Regional sobre Educación Superior Intercultural de América Latina y el Caribe, Pátzcuaro, Michoacán, 2009.

CGEIB. Manual de Procedimientos de la Coordinación General de Educación Intercultural y Bilingüe, México, Coordinación General de Educación Intercultural y Bilingüe, SEP, 2012.

Cordera, R. "Más allá de la focalización. Política social y desarrollo en México", en Nueva Sociedad, núm. 215, mayojunio, 2008, pp. 95-110.

Chiroleu, A. "La inclusión en la educación superior como política pública: tres experiencias en América Latina", en Revista Iberoamericana de Educación, núm. 48/5, 2009, pp. 1-15.

Deance, I., y Vázquez V., V. "La lengua originaria ante el modelo intercultural en la Universidad Intercultural del Estado de Puebla”, en Cuicuilco, México, vol.17 núm. 48, 2010, pp. 35-47.

Didou A., S. "Los Programas de educación superior indígena y la cooperación internacional en México, 2002-2013", en S. Didou A. (Ed.), Los Programas de Educación Superior Indígena en América Latina y en México: Componentes Tradicionales y Emergentes, México, UNESCO-IESALC, CONALMEX, OBSMAC, 2014, pp. 59-79.

Didou A., S., y Remedi A., E. Pathways to higher education. Una oportunidad de educación superior para jóvenes indigenas en México, México, ANUIES, 2006.

Dietz, G. "Intercultural universities in Mexico: empowering indigenous peoples or mainstreaming multiculturalismo", en Intercultural Education, Focus, vol. 20, núm. 1, 2009, pp. 1-4, doi: 10.1080/14675980802700623.

Dietz, G. Multiculturalismo, interculturalidad y diversidad en educación: una aproximación antropológica, México, Fondo de Cultura Económica, 2012. 
Dietz, G. "Educación intercultural en México", en CPU-e, Revista de Investigación Educativa, México, Universidad Veracruzana, vol. 18, 2014a, pp. 162-171.

Dietz, G. "Hacia una educación superior intercultural en México", en México Social, México, CEIDAS, 2014b. Disponible en http:// mexicosocial.org/index.php/secciones/especial/item/438hacia-una-educacion-superior-intercultural-en-mexico. Fecha de acceso, julio de 2015.

Dietz, G., y Mateos C., L. S. Interculturalidad y educación intercultural en México: un análisis de los discursos nacionales e internacionales en su impacto en los modelos educativos mexicanos, México, SEP, Coordinación General de Educación Intercultural y Bilingüe, 2011.

Franco, R. "Los paradigmas de la política social en América Latina”, en C. Arteaga B. y S. Solís (Eds.), La política social en la transición, México, UNAM, Escuela Nacional de Trabajo Social, 2001, pp. 18-38.

González A, E. "Acerca del multiculturalismo, la educación intercultural y los derechos indígenas en las Américas", en CPU-e, Revista de Investigación Educativa, México, Universidad Veracruzana, vol. 9, 2009, pp. 44-55.

González G., J. A. "Reforma al artículo $4^{\circ}$ constitucional: Pluralidad cultural y derecho de los pueblos indígenas", en Boletin Mexicano de Derecho Comparado, México, Instituto de Investigaciones Jurídicas, UNAM, núm. 79, 1994.

González G., J. A. El Estado y las etnias nacionales en México: la relación entre el derecho estatal y el derecho consuetudinario, México, Instituto de Investigaciones Jurídicas, UNAM, 1995.

González G., J. A. Derecho indígena, México, Instituto de Investigaciones Jurídicas, UNAM/McGraw-Hill, 1997.

González G., J. A. "El convenio 169 de la Organización Internacional del Trabajo sobre derechos de los pueblos indígenas y la obligaciones de México con su ratificación", en Boletín Mexicano de Derecho Comparado, México, Instituto de Investigaciones Jurídicas, UNAM, núm. 96, 1999.

González G., J. A. "Las iniciativas de reformas constitucionales en materia indígena en México", en Boletín Mexicano de Derecho Comparado, México, Instituto de Investigaciones Jurídicas, UNAM, núm. 97, 2000. 
González G., J. A. (2002). "La reforma constitucional en materia indígena”, en Cuestiones constitucionales: Revista mexicana de derecho constitucional, núm. 7, 2002, pp. 254-259.

González O, F. "La construcción de un modelo de educación superior intercultural. La Universidad Intercultural", en Ciencia Ergo Sum, México, UAEM, vol. 11, núm. 3, 2004, pp. 303-307.

González O., F. "Cultura y desarrollo desde la interculturalidad. Breve recuento de la primera universidad intercultural de México", en Ra Ximhai, México, Universidad Autónoma Indígena de México, vol. 3, núm. 2, 2007a, pp. 243-272. Hernández, M. "Sobre los sentidos de multiculturalismo e interculturalismo”, en Ra Ximhai, México, Universidad Autónoma Indígena de México, vol. 3, núm. 2, 2007, pp. 429-442.

Hevia R., R., Hirmas R., C., Treviño, E., y Marambio V., P. Politicas educativas de atención a la diversidad cultural: Brasil, Chile, Colombia, México y Perú, Chile, UNesco, 2005.

Huerta M., M. G., y García P., L. "Cultura escrita en un contexto intercultural: La Universidad Intercultural del Estado de Puebla”, en Uaricha. Revista de Psicología, México, Facultad de Psicología de la Universidad Michoacana de San Nicolás de Hidalgo, vol. 10, núm. 23, 2013, pp. 73-88.

INEE. El derecho a una educación de calidad, Informe 2014, México, Instituto Nacional de Evaluación Educativa, 2014.

Jusidman, C. "Desigualdad y política social en México", en Nueva Sociedad, Bs. As., Argentina, núm. 220, 2009, pp. 190-206.

Kent S., R. "Una visión conceptual de los procesos de cambio en las políticas y los sistemas de educación superior”, en R. Kent $\mathrm{S}$. (Ed.), Las politicas de educación superior en México durante la modernización: un análisis regional, México, ANUIES, 2009, pp. 13-38.

Lehmann, D. "Dilemas de las universidades interculturales de Mexico", en IdeAs. Idées d'Amériques, Francia, Instituto de las Américas, vol. 2, 2012. Disponible en http://ideas. revues.org/234. Fecha de acceso, junio de 2015.

Lehmann, D. "Intercultural Universities in Mexico: Identity and Inclusion", en Journal of Latin American Studies, U. S., 
Cambridge University Press, vol. 45, núm. 4, 2013, pp. 779-811.

López B., F. Rostros y caminos de los movimientos indigenas en México, México, MC Editores, 2005.

López, L. E. "Interculturalidad, educación y política en América Latina: perspectivas desde el Sur. Pistas para una investigación comprometida y dialogada”, en L. E. López (Ed.), Interculturalidad, educación y ciudadania: perspectivas latinoamericanas, Bolivia, Fundación para la Educación en Contextos de Multilingüismo y Pluriculturalidad, 2009, pp. 129-220.

Maldonado A., B. Comunidad, comunalidad y colonialismo en Oaxaca: la nueva educación comunitaria y su contexto, México, Colegio Superior para la Educación Integral Intercultural de Oaxaca, 2006.

Mateos C., L. S., y Dietz, G. "Universidades Interculturales en México”, en M. Bertely B, G. Dietz y M. G. Díaz T. (Eds.), Multiculturalismo y educación, 2002-2011, México, ANUIES, 2013, pp. 245-272.

Mateos C., L. S., Mendoza Z., R. G., y Dietz, G. "Diversidad e interculturalidad en la educación superior convencional", en M. Bertely B, G. Dietz y M. G. Díaz T. (Eds.), Multiculturalismo y educación, 2002-2011, México, ANUIES, 2013, pp. 213-244.

Maurer Á., E. "La política educativa indigenista”, en Revista Latinoamericana de Estudios Educativos, México, CEE, vol. 40, núms. 3 y 4, 2010, pp. 261-288.

Mendoza Z., R. G. "Gestión intercultural en el ámbito de los derechos humanos en México: retos de la Universidad Veracruzana Intercultural", en Cuadernos Interculturales, Chile, Universidad de Playa Ancha, vol. 7, núm. 13, 2009, pp. 125-140.

Mendoza Z., R. G. "Interculturalización de políticas para la educacion superior en Mexico: el caso de la Universidad Veracruzana Intercultural", en Uaricha. Revista de Psicología, México, Facultad de Psicología de la Universidad Michoacana de San Nicolás de Hidalgo, vol. 10, núm. 21, 2013, pp. 56-77. 
Meyer, L., y Maldonado A., B. Entre la normatividad y la comunalidad: experiencias educativas innovadoras del Oaxaca indigena actual, México, Fondo Editorial, IEEPO, 2004.

Molina F., N. "Los jóvenes en las universidades interculturales: la experiencia de integración al sistema universitario en la Universidad Intercultural del Estado de México, UIEM", en Universidades, México, UDUAL, vol. 62, núm. 54, 2012, pp. 4-19.

Morgan, R. "Advancing Indigenous Rights at the United Nations: Strategic Framing and Its Impact on the Normative Development of International Law", en Social \& Legal Studies, Reino Unido, vol. 13, núm. 4, pp. 481-500, doi: 10.1177/0964663904047330

Ordóńez B., G. M. La politica social y el combate a la pobreza en México, México, Centro de Investigaciones Interdisciplinarias en Ciencias y Humanidades, UNAM, 2002.

Pérez R., M. L. “¿De qué hablamos cuando nos referimos a lo intercultural. Reflexiones sobre su origen, contenidos, aportaciones y limitaciones", en L. R. Valladares, M. L. Pérez R. y M. Zarate (Eds.), Estados plurales: los retos de la diversidad y la diferencia, Mexico, UAM, Unidad Iztapalapa, 2009, pp. 251-289.

Ramírez B., J. J. "Los organismos internacionaes y los derechos de los pueblos indígenas", en S. Didou A. (Ed.), Los Programas de Educación Superior Indigena en América Latina y en México: Componentes Tradicionales y Emergentes, México, UNESCO-IESALC, CONALMEX, OBSMAC, 2014, pp. 29-58.

Redacción. "Ediles de la Sierra Norte se unen para cambiar sede de la Universidad Indígena”, en El Sol de Puebla, 11 de julio de 2005.

Reimers, F. "Educación, desigualdad y opciones de política en América Latina en el siglo XXI", en Revista Iberoamericana de Educación, OEI, vol. 23, 2000, pp. 21-50.

Rubio O., J. La politica educativa y la educación superior en México: 1995-2006. Un balance, México, FCE, 2006.

Sandoval F., E. A., y Guerra G., E. "La interculturalidad en la educación superior en México", en Ra Ximhai, México, Universidad Autónoma Indígena de México, vol. 3, núm. 2, 2007, pp. 273-288. 
Sandoval, J.C., González, O., y Téllez, S. “Intercultural University of Veracruz: a holistic project promoting intercultural education", en Intercultural Education, Focus, vol. 17, núm. 5, 2006, pp. 499-505, doi: 10.1080/14675980601063843

Sarmiento S., S. "El Consejo Nacional de Pueblos Indígenas y la política indigenista”, en Revista Mexicana de Sociología, México, Instituto de Investigaciones Sociales, UNAM, vol. 47, núm. 3, 1985, pp. 197-215.

Schmelkes, S. "Intercultural universities in Mexico: progress and difficulties", en Intercultural Education, Focus, vol. 20, núm. 1, 2009, pp. 5-17, doi: 10.1080/14675980802700649 Secretaría de Salud. "Salud y nutrición para población marginada rural e indígena”. Disponible en www.salud.gob.mx/ unidades/dgpfs/pueblosindigenas/Pueblos\%20Indigenas. pdf. Fecha de acceso, 15 de julio de 2015.

SEP. Acuerdo por el que se establece la Coordinación General de Educación Intercultural Bilingüe, México, SEP, 2001.

Sieder, R. "Introduction", en R. Sieder (Ed.), Multiculturalism in Latin America: indigenous rights, diversity and democracy, Basingstoke, Palgrave Macmillan, 2002a, pp. 1-24.

Sieder, R. Multiculturalism in Latin America: indigenous rights, diversity and democracy, Basingstoke, Palgrave Macmillan, 2002b.

Tuirán, R. "La educación superior en México, 2006-2012. Un balance inicial", en Diario Milenio, 27 de septiembre de 2012.

Valdez R., L. B., y Romero L., F. "Diversidad y convivencia intercultural en estudiantes de la Universidad Autónoma Indígena de México, Unidad Mochicahui”, en Ra Ximhai, México, Universidad Autónoma Indígena de México, vol. 7, núm. 3, 2011, pp. 427-436.

Viaña, J., Tapia, L., y Walsh, C. Construyendo interculturalidad crítica, Bolivia, Instituto Internacional de Integración, Convenio Andrés Bello, 2010.

Vitale, E. Liberalismo y multiculturalismo: un desafio para el pensamiento democrático, México, Océano, 2004.

Von Groll, M., Keyser O., U., y Silva C., E. "Formación de maestros indígenas y no indígenas para la educación indígena e intercultural", en M. Bertely B., G. Dietz y M. G. Díaz T. (Eds.), Multiculturalismo y educación, 2002-2011, México, ANUIES, 2013, pp. 85-114. 